\title{
A context-aware knowledge map to support ubiquitous learning activities for a u-Botanical museum
}

\author{
Shu-Lin Wang \\ National Taichung University of Science and Technology \\ Chia-Chen Chen \\ National Chung Hsing University
}

Zhe George Zhang

Simon Fraser University

\begin{abstract}
Recent developments in mobile and wireless communication technologies have played a vital role in building the u-learning environment that now combines both real-world and digital learning resources. However, learners still require assistance to control real objects and manage the abundance of available materials; otherwise, their mental workload could become so high that learning becomes less effective. The learner is the priority in every learning situation and is, therefore, a crucial factor in executing u-learning. This study presents a u-learning system that integrates context awareness and ontological technology to design a context-aware knowledge map (CAKM) to improve learning efficiency. A case study of an Orchid Island botanical ecosystem course was conducted in classrooms and at the Botanical Garden of National Museum of Natural Science in Taiwan. Participants were university teachers and students. A questionnaire based on the technology acceptance model (TAM) theory was designed and used to measure the willingness for adoption or usage of the proposed system. The results demonstrate that this innovative approach can enhance learning intention. The results also indicate that this CAKM not only substantially improves the effectiveness of subject learning but also enhances the usability of u-learning systems in the museum environment.
\end{abstract}

\section{Introduction}

Current wireless communication, sensors, and mobile technologies provide opportunities for learning strategies by integrating real-world learning environments with the resources of the digital world (Chen \& Huang, 2012; Chen \& Lin, 2014; Looi et al., 2010; Wang \& Wu, 2011). Context-aware ubiquitous learning (u-learning) has been proposed as an extension of contextual awareness technology. Pegrum, Oakley, and Faulkner (2013) pointed out that u-learning places less emphasis on mobility and contextual independence, and more emphasis on the situated, context-aware learning that mobile devices enable. U-learning is a new learning mode that promotes on-demand, hands-on or minds-on learning, authentic learning, and so on. The development of this learning mode has occurred mainly in the fields of social learning, situated learning, and knowledge building (Looi et al., 2010). However, authentic learning, or learning by experience, is a pedagogical approach in which students discover, and discuss concepts and relationships, connecting them to the real world in meaningful ways (Donovan, Bransford, \& Pellegrino, 1999). This authentic learning style is defined as a coherent, meaningful, and purposive activity (Brown, Collins, \& Duguid, 1989). An authentic learning environment must incorporate scaffolds for learners to improve and advance to new levels of development (Roth, 1992). In addition, the character of u-learning technology provides the benefits of many authentic environments, such as permanency, accessibility, immediacy, interactivity, and the situating of instructional activities (Cheng \& Marsic, 2002; Dieterle, 2004). Thus, the advantages of ulearning are suitable for application during authentic learning activities.

Numerous educational researchers have conducted studies on how to use context-aware computing to build u-learning systems. However, learners still require assistance with controlling real objects and managing the abundance of available materials. Without this assistance, their minds could become overloaded enough to negatively affect their u-learning achievement. Results from research conducted by Firat and Kuzu (2011) show that the current web environment provides great amounts of learning information and diverse chances for information browsing; however, this often leads to disorientation and cognitive overload for users (Firat \& Kuzu, 2011). Cognitive load theory (CLT) supports the idea that effective learning materials lead learners in using cognitive resources on related learning activities to achieve the effects of learning assistance, rather 
than preliminaries to learning (Chandler \& Sweller, 1991). CLT reveals that how to lead users to effectively utilise cognitive resources on context-aware learning activities is a factor to be considered when constructing u-learning systems. Ubiquitous computing is a model of human-computer interaction that reinforces the use of computers by making many computers useful throughout the real environment, although they remain invisible (El-Bishouty, Ogata, Rahman, \& Yano, 2010; Kwon, Choi, \& Kim, 2007). Weiser (1993) also showed the importance of human-computer interaction in building a u-learning environment. From a constructivist perspective, learning is an interactive and constructive process. With the development of technology, the features of web media can support this and provide opportunities for immediate interactions (Sun \& Hsu, 2012). Therefore, developing a u-learning system not only supports learners with innovative technology to address real-world problems but also enables the system to be interactive in its relationship with learners (Chu, Lee, \& Tsai, 2010; Hwang, Shi, \& Chu, 2011; Yang, Okamoto, \& Tseng, 2008).

Pachler, Cook, and Bachmair (2010) showed that authentic learning emphasises the ability to make information meaningful to students. Meaning is the most critical aspect of learning, and cannot be transferred by simply using signs, images, or words (Pachler et al., 2010). To make a u-learning environment and its teaching resources more meaningful to learners, many educational researchers have applied an ontological approach to build e-learning assistance tools (Chu et al., 2011). Chu et al. (2011) showed that the navigation interface of an ontologically based concept map learning system, the abstract of knowledge representation, and dynamic learning content can prevent learners from losing information while searching. This is particularly true for situations involving abundant learning resources, for which learners require detailed knowledge of the mobile complex to complete their tasks. Knowledge represented in graphical form enables learners to overcome this type of problem (Tergan, Gräber, \& Neumann, 2006). Therefore, to organise numerous digital teaching resources or objects while effectively reducing the cognitive overload for learners, adding a semantic web, ontology, and taxonomy to the u-learning system is useful.

As the basis for building a digital learning resource library, this study applied the botany digital archives of Taiwan's most famous museums of natural science and the ontology of botany developed by experts in the botanical domain. A user interface that enables keyword searches has been built by botanical museums in recent years. However, Kalyuga, Ayres, Chandler, and Sweller (2003) noted that learning guidance might be necessary under certain circumstances when the material is being presented to learners with less experience. General users who are not botanists or who do not have background knowledge of botanical classification find it especially difficult to index digital learning resources with a keyword retrieval aid interface. Therefore, this study combined the sensing technologies of radio frequency identification (RFID) to develop a knowledge retrieval aid and graphical interface with situation-sensing ability: a context-aware knowledge map (CAKM). To be specific, the purpose of this research was to utilise the digital resources of botany in combination with the actual learning environments of the arboretum to develop a u-learning system. On one hand, RFID technology will be used to build digital learning with environment sensing to help the learners acquire digital learning resources and enhance their learning motivation while they are in the actual arboretum. On the other hand, it is hoped that the development of a CAKM can lead learners in accessing the digital resources of botany. As a result, the beginners in this field can acquire the digital learning resources they need without prior knowledge of the categories of botany; meanwhile learners have their learning process recorded by the CAKM. The participants of the research are university students who do not major in the domain of botany knowledge so the effects of a CAKM on their learning efficiencies can be studied.

\section{Relevant research}

Many studies in recent years have applied context-aware computing technology to developing information services and e-learning. An example is a context-aware mobile portal (CAMP) that involves using contextaware technology to collect user preferences, location, and information about climates (Mandato, Kovacs, Hohl, \& Amir-Alikhani, 2002). Chen, Kao, Sheu, and Chiang (2008) and Yang et al. (2008) applied ucomputing technology to develop a ubiquitous learning environment to connect learners to learning content and learning services seamlessly. Lanir, Kuflik, Wecker, Stock, and Zancanaro (2011) examined proactive and passive context-awareness technologies in a location-aware mobile museum guide. However, the learner's current context must be ascertained for ubiquitous computing to provide timely and accurate 
learning resources. Chu, Hwang, Tsai, and Tseng (2010) conducted an experiment in a u-learning environment in an elementary school natural science course. Their results show that the learning tasks are more complex for learners in a new learning situation when they must face the dual tasks of searching for real-world and digital-world resources simultaneously without appropriate assistance. In addition, Hwang et al. (2011) showed that m-learning provides the opportunity for combining real-world and digital-world resources, but the resulting performance does not achieve the expected effect without proper tools being used to help learners organise their observations in a real learning environment. To address this problem, Hwang et al. (2011) also proposed an interactive concept-map-oriented approach to support mobile learning. The results of their experiments show that this approach improves not only learning attitudes but also achievement. Therefore, developing a u-learning system not only innovatively helps learners address real-world problems but also enables them to interact with the system.

E-learning requires considering new course content, organising content, establishing new resources, and defining new roles for both learners and instructors (Abel et al., 2004). Therefore, the importance of applying ontologies in e-learning systems has gained more attention recently (Yalcinalp \& Gulbahar, 2010). Ontology is not only a part of the knowledge representation field but also a discipline (Sowa, 2000). The information technology and artificial intelligence communities have many definitions of ontology, the two most popular being "a formal explicit specification of a shared conceptualization” or "an abstract view of the word we are modelling” (Gruber, 1993, pp. 199-200). The hierarchical links between entities and other semantic relations can be expressed by applying ontology (Yalcinalp \& Gulbahar, 2010). Educational researchers have proposed numerous learning assistance tools to develop e-learning systems (Aroyo \& Dicheva, 2004). The ontology-based concept map learning system involves using visual navigation through a concept map to facilitate digital learning (Chu et al., 2011). Henze, Dolog, and Nejdl (2004) proposed an adaptive educational hypermedia systems framework on the semantic web. Gascueña, Fernández-Caballero, and González (2006) introduced domain ontology to describe learning materials consisting of a course that provides adaptive e-learning environments and shareable educational resources. Most of these studies have applied ontology to the e-learning system. However, studies on how to apply ontology to a context-aware u-learning system in a relatively complex learning environment have been relatively scarce. Therefore, this study attempts to develop a location-aware learning environment with appropriate learning assistance tools for offering learners a more authentic learning experience.

\section{U-learning system architecture}

This study applied the botany digital archives of Taiwan's most popular museums of natural science and the ontology of botany developed by experts in the botanical domain as the basis for building a learning resource database. Thus, this study presents a u-learning system that includes the following functions: a SCORM-based learning resources database, a situation-sensing function, a CAKM, a personalised learning profile function, a personalised learning diary, and a blog function to share learning experiences. Figure 1 shows the framework of the u-learning system. 


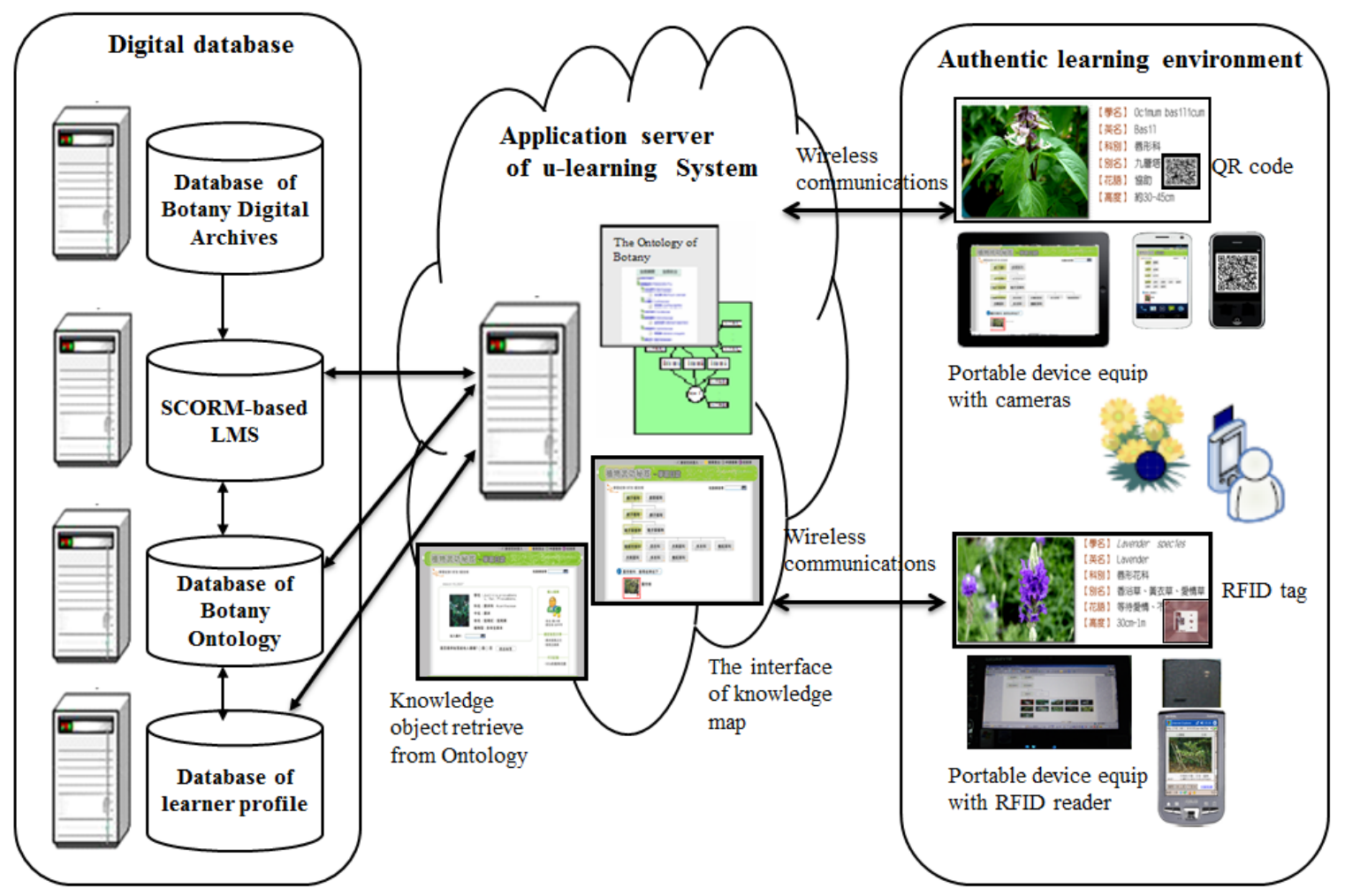

Figure 1. The framework of the context-aware u-learning system

\section{Designing a CAKM}

To enhance the ability of learners to retrieve learning resources in an authentic learning environment, this study presents the design of the knowledge retrieval aid tools. The first step involved converting the botany digital archives into a SCORM-based learning resources database. This study applied the botanical knowledge ontology, based on the botanical taxonomy already established by botanists at the National Museum of Natural Science. The system comprises a botanical knowledge map, built in the form of a hierarchical ontology and encompasses 625 plant knowledge objects of the phylum spermatophyta. The map also includes eight records from the gymnospermae and 617 records from the angiospermae. The taxonomic schematics of the botanical ontology are shown in Figure 2.

Researchers have been proposing semantic web technologies, ontologies in particular, primarily for improving learning object metadata (Berners-Lee, Hendler, \& Lassila, 2001; Gašević, Jovanović, \& Devedžić, 2007). Firat and Kuzu (2011) mentioned in their research on the semantic web that the emerging semantic web has become the solution to cognitive loads for learners indexing mass amounts of digital information. The botany domain ontology used in this study was designed as a semantic web using information technology. The ontology approach proposed by Uschold and Gruninger (1996) was used to construct a knowledge map in five stages: data pre-processing, case knowledge structuring, establishment of a domain concept hierarchy, ontological formalisation, and implementation. The source of the domain ontology learning materials was previously developed by expert botanists and processed using XML and metadata technologies to develop a semantic and graphical knowledge search interface. This was connected to a back-end database and a visual graphical interface knowledge map. 


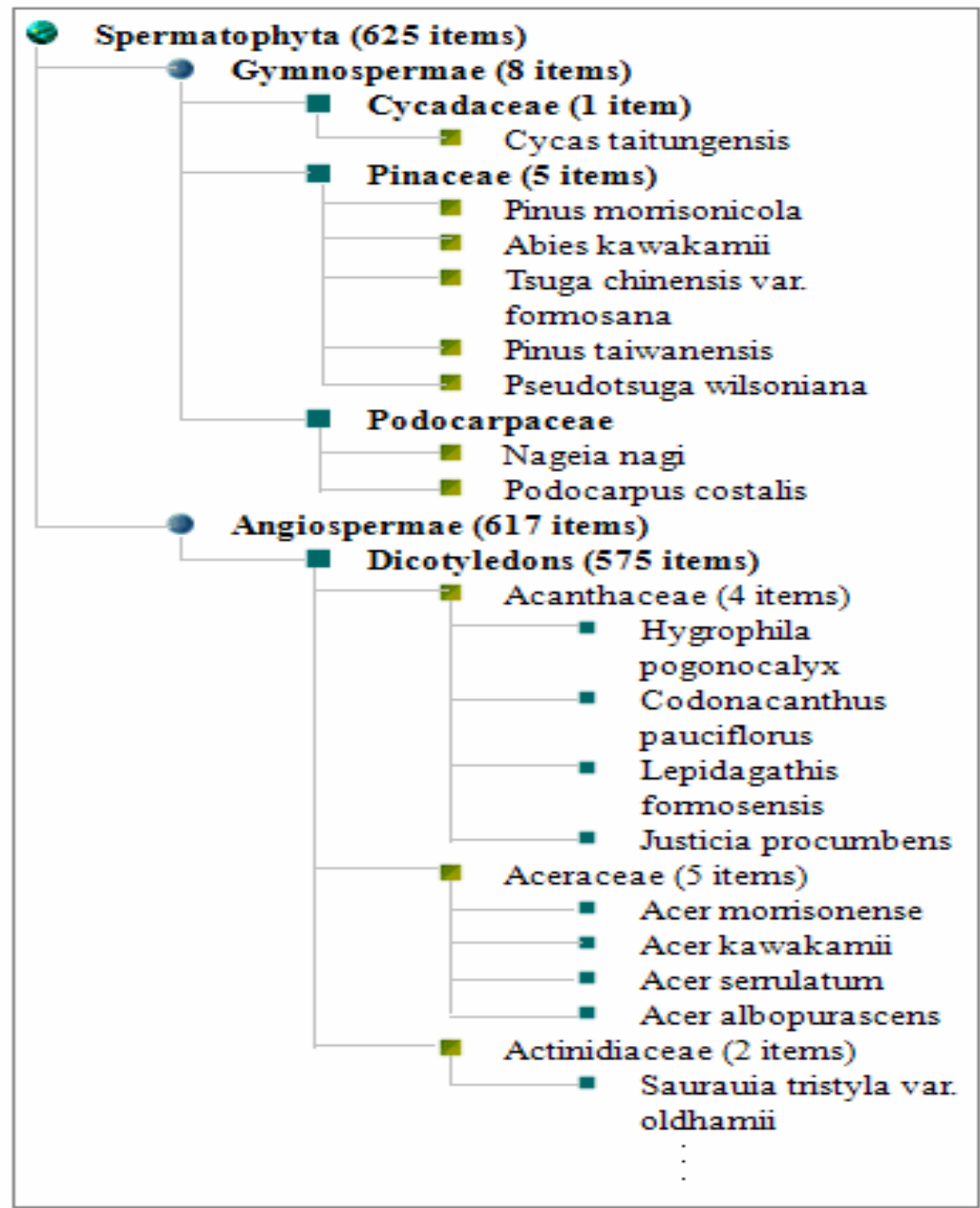

Figure 2. Ontology of the knowledge map

\section{System environments and setting}

To perform a context-aware function, the proposed method combines RFID technology and QR code technology to achieve a situation awareness effect. This study used the RFID, which is commonly used in Taiwanese museums, to conduct experimental tests that integrated RFID and ontology. A graphical navigation interface was developed with a situation-sensing function to form a CAKM. An RFIDidentifying function was installed on each target knowledge object at the lowest level in the domain ontology structure and the corresponding RFID tag identifiers were built. The learners first read the identifier tag of the plants using the RFID reader on the mobile device, and then used this as a key to search the corresponding knowledge objects and browse the learning resources. Using RFID readers on mobile devices (such as a PDA or Eee PC) and obtaining learning resources by using a CAKM allows learners to detect the objects to be learned, such as natural plants, in a real environment. Figure 3 shows a typical screen view of the CAKM. In this case, the learners can sense the RFID tag of False Indian Almond and then obtain related information about the plant on the mobile devices. In addition, learners can also understand its hierarchical ontology and which knowledge object has been learned. In this case, the hierarchical ontology of False Indian Almond is spermatophyta, angiospermae, monocotyledons, and neonauclea reticulata, up to down respectively. 


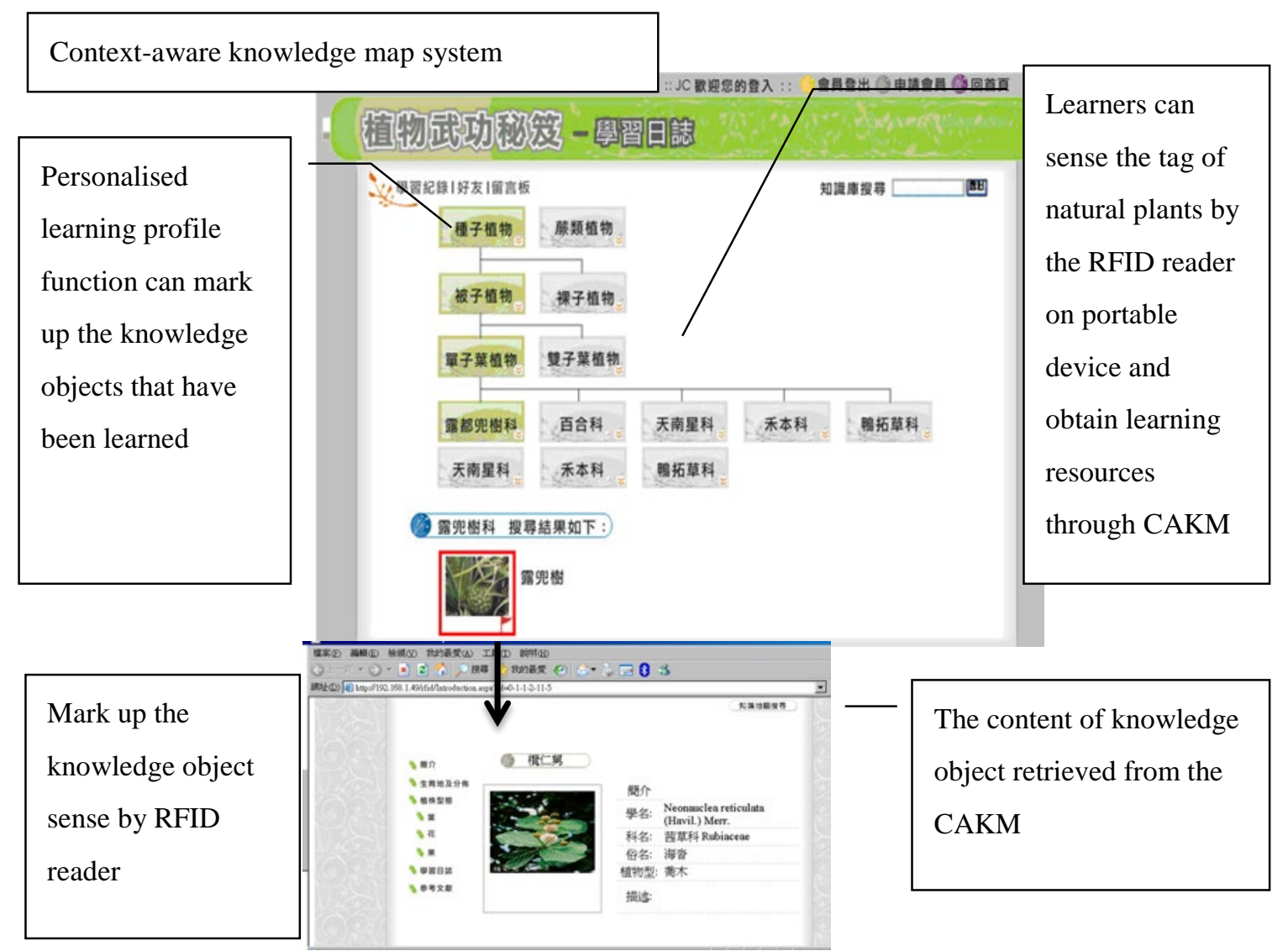

Figure 3. Context-aware knowledge map retrieval aid screen

The equipment used for this experiment are mobile communications devices (Gigabyte Eee PC) equipped with an RFID reader and capable of wireless connection to an learning management system server at a wireless access point set up on the site. The communications devices equipped with an RFID reader are shown in Figure 4. The learning objects used in the experimental learning process were pre-assigned plants, all with RFID tags. Every subject was given a learning task description and an evaluation questionnaire about the knowledge retrieval aid and user interface. The learning model applied in this experiment was mainly problem based. This means that the subject was asked to find the answer to a question using the knowledge retrieval aid tools. Participants were able to use a knowledge retrieval aid interface to search the content of the knowledge objects in the learning resources database in a problem-based learning process to further complete the learning tasks.

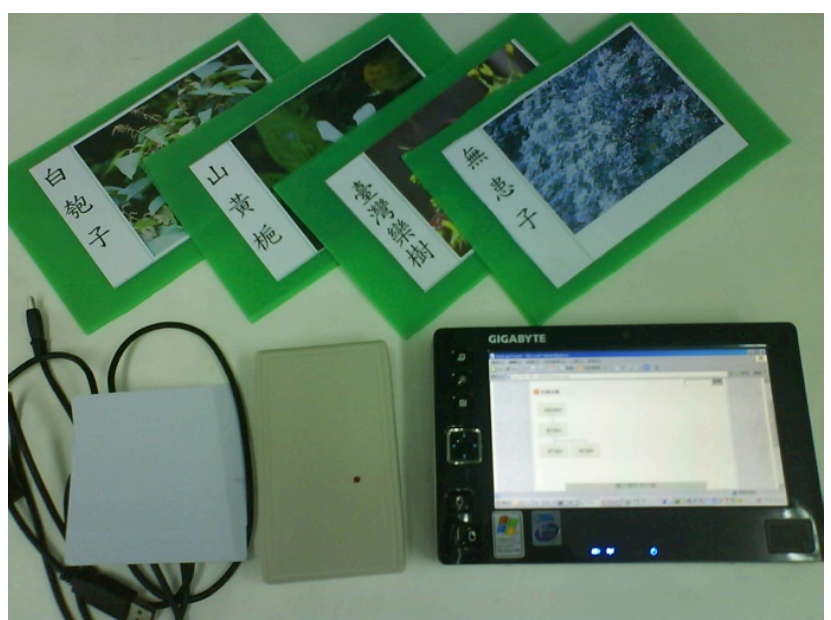

Figure 4. Communications devices and RFID reader 


\section{Evaluation}

To evaluate the effectiveness of the CAKM retrieval aid, a series of controlled experiments was conducted to compare the learning achievements and attitudes of participants who participated in a context-aware ulearning activity with a different knowledge retrieval interface. After the experiments were performed, a questionnaire survey was provided to evaluate the effectiveness of the CAKM in improving student learning motivation and effectiveness.

\section{Experimental methods}

The experiments were conducted in a real environment in the botanical garden of a museum of natural science. Specific plants were pre-assigned as learning targets in the learning process, and the participants could also use the knowledge retrieval aid provided by a learning system through their hand-held devices using a touch pen stylus. Participants were asked to use the knowledge retrieval aid to investigate the content of the vascular plants learning resources library during the experiment, and to answer the questions that appeared on their mobile device screens. The system automatically recorded the time participants spent on learning and answering, and their answers. These data were sent to the back-end database as records.

Fourteen items in the ease of use and usefulness scale were modified from those of Davis $(1989,1993)$ to describe the functions and features of interactive knowledge retrieval aids. The questionnaire survey was administered to all students during the final class. A 7-point Likert scale was used for all questions, ranging from 1 (strong disagreement) to 7 (strong agreement). The related variables were tested using the KaiserMeyer-Olkin (KMO) measure of sampling adequacy and the Bartlett test of sphericity. The KMO value test result was 0.898 and, because it is greater than 0.7 , there was clear correlation between the variables available for factor analysis. The Bartlett test of sphericity results were also significant. Factor analysis (applying principal component analysis, and excluding items with a loading of less than 0.5) resulted in the identification of three main factors from 14 questions, as seen in Table 2. These factors were categorised as "intent to use", "usefulness", and "ease of use". The cumulative explained variance of the factors reached 82.788\%. (See Table 1 for full questionnaire.)

Table 1

The usability evaluation questionnaire

\begin{tabular}{|c|c|c|}
\hline Dimensions & $\begin{array}{l}\text { Item } \\
\text { no. }\end{array}$ & Descriptions of measures \\
\hline \multirow[t]{5}{*}{ Usefulness } & PU01 & The aid of an e-learning system is helpful in all learning situations. \\
\hline & PU02 & The context awareness of the m-learning system helps me with practical learning. \\
\hline & PU03 & $\begin{array}{l}\text { The m-learning system's knowledge retrieval aid can improve my learning } \\
\text { effectiveness. }\end{array}$ \\
\hline & PU04 & $\begin{array}{l}\text { The design of the m-learning user interface can improve my learning } \\
\text { effectiveness. }\end{array}$ \\
\hline & PU05 & The knowledge guide units satisfy my learning requirements. \\
\hline \multirow[t]{5}{*}{ Ease of use } & PE01 & The context awareness function is easy to use. \\
\hline & PE02 & The m-learning user interface is smooth. \\
\hline & PE03 & The m-leaning user interface is clear and definite. \\
\hline & PE04 & The entire m-learning system is easy to use. \\
\hline & PE05 & The m-leaning system's knowledge retrieval aid is easy to use. \\
\hline \multirow{4}{*}{$\begin{array}{l}\text { Intention to } \\
\text { use }\end{array}$} & IU01 & The m-learning system's user interface design can increase my intention to learn. \\
\hline & IU02 & $\begin{array}{l}\text { The m-learning system's knowledge retrieval aid increases my intention to use the } \\
\text { system. }\end{array}$ \\
\hline & IU03 & The m-learning system's context awareness increases my intention to learn. \\
\hline & IU04 & The m-learning system increases my intention to use it. \\
\hline
\end{tabular}


Table 2

Factor analysis (Note: suppress absolute values $<0.50$.)

\begin{tabular}{cccc}
\hline Variable & Usefulness & Ease of use & Intention to use \\
\hline PE03 & .891 & & \\
PE05 & .847 & & \\
PE04 & .838 & & \\
PE02 & .832 & & \\
PE01 & .739 & .878 & \\
PU05 & & .841 & \\
PU01 & & .708 & \\
PU03 & & .671 & \\
PU04 & & .558 & .912 \\
PU02 & & & .823 \\
IU02 & & & .795 \\
IU01 & & & .615 \\
IU03 & & & \\
IU04 & & & \\
\hline
\end{tabular}

The Pearson coefficient determines the relativity of different variables, and is used here to analyze the relationships between usefulness, ease of use, and intent to use with results listed in Table 3. Based on these results, usefulness is significantly related to ease of use and intent to use. This indicates that, in a ubiquitous learning environment, more useful information can be provided, and thus more users will be willing to use it. In addition, the ease of use is significantly related to intent to use and has higher correlation than usefulness. It means, the easier operation, the higher the intention will be. After the factor analysis and Pearson coefficient analysis, this experiment has suitable validity and can be used to further statistical analysis.

Table 3

Correlation matrix among the variables

\begin{tabular}{lccc}
\hline \multicolumn{1}{c}{ Construct } & Usefulness & Easy of use & Intention to use \\
\hline Usefulness & 1 & & \\
Easy of use & $.582^{* *}$ & 1 & \\
Intention to use & $.801^{* *}$ & $.610^{* *}$ & 1 \\
\hline
\end{tabular}

Assessments to evaluate the learning effectiveness were designed by participant teachers and updated annually according to instructional requirements. The assessments have superior validity under these conditions. This study used the Cronbach's $\alpha$ coefficient to evaluate the internal consistency reliability of the assessments (Mehrens \& Lehmann, 1987). The Cronbach's $\alpha$ coefficient ranges between 0 and 1 . Nunnaly (1978) stated that 0.7 is an acceptable minimal reliability coefficient. In the study, the Cronbach's $\alpha$ value for each factor was above 0.8 , and the Cronbach $\alpha$ coefficient value for the overall was greater than 0.9. Therefore, all questionnaires used in this study showed adequate reliability. To increase the validity, the wording and meaning of the questionnaires were reviewed and revised by an e-learning expert. In addition, the revised questionnaires were then pilot tested and were modified according to participants' feedback. A one-way ANOVA test was applied to analyze the answers to the questionnaire, to determine the adoption willingness for the proposed CAKM, and to determine student learning attitudes.

\section{Participants}

This study involved the cooperation of the botanical garden of a museum of natural science in Taiwan. The subjects of this experiment were non-botany majors. They were university students, on average 24 years old and randomly assigned into three groups. The participants all wore eyeglasses, and their sight after correction was 0.8 or above; none were colour-blind. Ten participants were assigned at random to each of three experiment groups: the CAKM retrieval group, the knowledge map (KM) retrieval group, and the traditional keyword retrieval group (Keyword). The meaning and difference of these three retrieval aid approaches are described in the following sections. 
The CAKM retrieval aid approach can provide a graphical navigation interface with a situation-awareness function developed by the integration of RFID technology and ontology in which a CAKM is used to conduct retrieval from the botany learning resource database. This CAKM provides a graphical search interface developed in accordance with ontological principles. It uses a knowledge map to retrieve data from the botany learning resource database. Using the RFID readers on their handheld devices, participants can collect the information stored on the plant tags. The system automatically locates and marks the node of the knowledge object matching that plant on the knowledge map. Participants can search the learning resource database by clicking on the node, and the system automatically feeds back the contents of the knowledge object requested.

The KM retrieval aid approach can provide a graphical search interface that was developed employing ontological principles, and uses a knowledge map to conduct retrieval from the botany learning resource database. The KM group participants match the plant objects in a real learning environment by manually operating the knowledge map provided by the browsing system to identify the class, family, genus and species of the plant corresponding to the ontological classification structure of the knowledge map. The knowledge object node is found using the ontological classification structure and the learning resource database is searched by manually clicking the node so that the system automatically feeds back the contents of the knowledge object requested.

The keyword retrieval aid (Keyword) approach is the traditional search method employing a keyword menu. Participants search the learning resources database by choosing the class, family, genus and species name of the plant on the menu. Participants find the plants in the real environment to make identification by manually choosing them to search the menu. The system automatically feeds back the contents of the knowledge object corresponding to the keywords chosen by the participant.

\section{Learning activities}

Taiwan's botany includes various species that are worthy of study and discussion. In this research, the learning topic was chosen for a course entitled “Orchid Island Botanical Ecosystem.” Taiwan’s outlying Orchid Island was selected. It was World Heritage listed in 1995 and is home to many unique plants because of its special geographic mountainous environment. The island is the only place in Taiwan where tropical rain forest plants can be seen. It is located on the northern boundary of the Southeast Asia forest system, one of the three biggest rain forests in the world. In addition, there are 26 plant species unique to this island. The learning goals of this course were understanding the natural environment and botanical ecosystem in Orchid Island; understanding the importance of the unique vascular plants of Orchid Island; understanding the relationship between Orchid Island and the South Pacific Ocean religion; and understanding the concept and manner of protecting and promoting the unique vascular plants of Orchid Island. The main learning purpose of this course was to cultivate problem-solving and knowledge construction capabilities of students.

Figure 5 shows the chronology of the data collection. In phase 1, the learning activities and processes of these experimental groups were introduced to all learners. Then, all learners were required to operate the RFID devices and become familiar with these wireless technologies. Subsequently, teachers were guided to provide classification knowledge of the botanical species based on the botanical knowledge ontology. They introduced the botanical concepts and species in the Orchid Island. After receiving fundamental knowledge of the plants in the Orchid Island botanical ecosystem, all the learners were asked to complete ten learning subjects on the u-Botanical museum. 


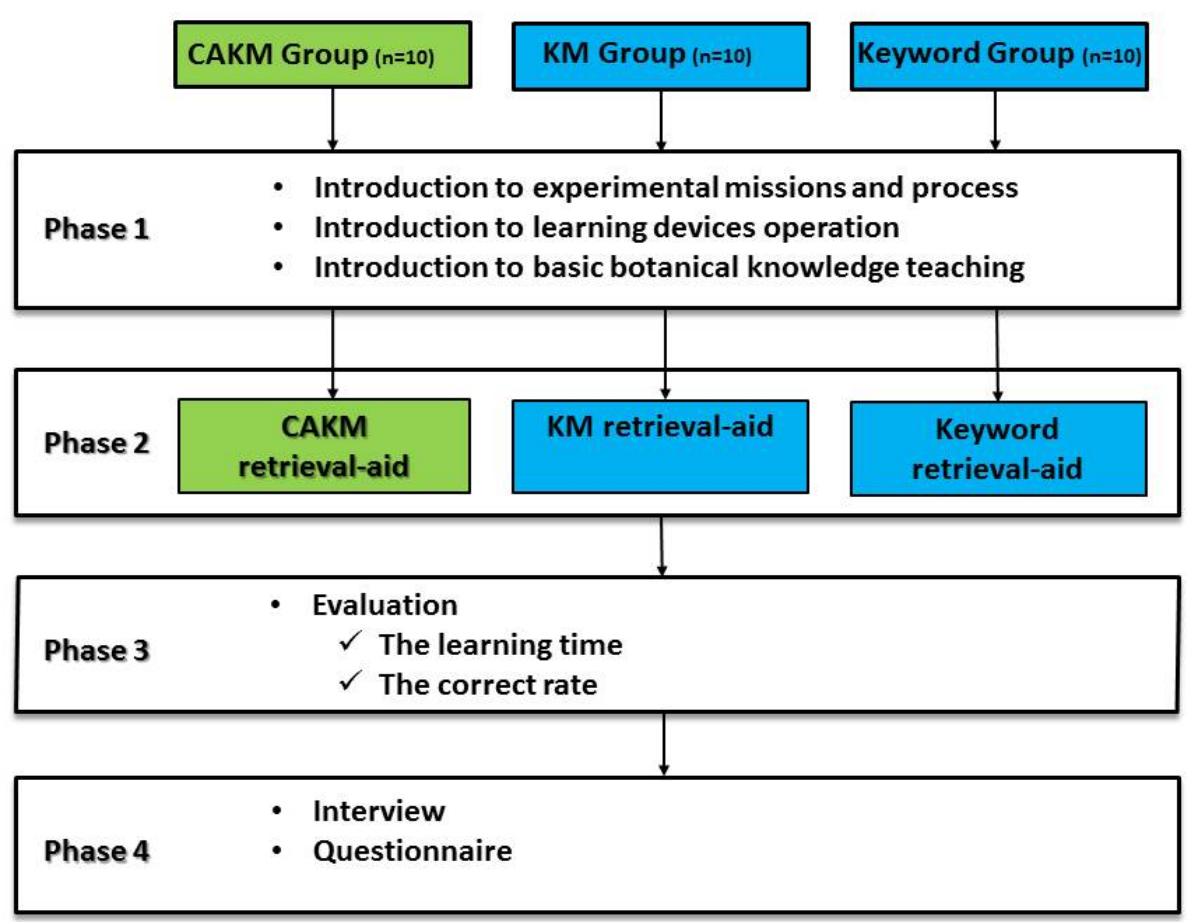

Figure 5. Research chronology

In phase 2, outdoor teaching was conducted in the Botanical Garden of the Museum of Natural Science in Taiwan. The CAKM students were required to observe the features of plants in the u-Botanical museum using the CAKM. The students in the KM and Keyword groups were guided to observe the plants through the KM or Keyword retrieval aid approaches. Subsequently, the CAKM group used PDAs equipped with an RFID reader, with which the CAKM can detect the knowledge ontology of each plant. This provided the students with relevant learning materials as soon as they approached a target plant.

In phase 3, after conducting the outdoor learning activity, learners in the three groups were asked to complete a post-test during these ten learning activities. The evaluation points were learning time and its correct rate. To collect the learning time, the system starts to record soon after the participant has received the question and pressed the confirm button on the interface. Recording continues until the subject answers the question. When the answer is submitted to the system, the end time for that question is automatically recorded. Participants can use the knowledge retrieval aid freely during the process to search for information that will help them to answer questions. The correct learning rate is expressed as the ratio of the number of correctly answered questions to the total number of questions. Finally, the CAKM group was asked to answer a 30-minute questionnaire on the u-Botanical museum. In the last phase, this study designed and used a questionnaire based on the technology acceptance model (TAM) theory to measure the willingness for adoption or usage of the proposed system. The goal of this experiment is to demonstrate how the proposed innovative approach can enhance student learning intention.

\section{Results}

A one-way ANOVA was performed on the learning time of the knowledge retrieval aid on each group. The ANOVA results are given in Table 4, and show that the main effect on each group on the learning time was significant differences $(F(2,14)=15.380, p=.000, p<.01)$. The results after multiple analysis show that the CAKM group results (mean $=42.26$ sec., $\mathrm{SD}=7.858$ ) were significant lower than those of the KM group (mean $=72.14$ sec., $S D=16.719)$ and the Keyword group (mean= 93.24 sec., $S D=17.280$ ) for learning time. The KM group (mean $=72.14$ sec., $\mathrm{SD}=16.719$ ) and Keyword group (mean = 93.24 sec., $\mathrm{SD}=17.280$ ) show no significant difference with respect to the learning time. 
Table 4

ANOVA of the learning time

\begin{tabular}{|c|c|c|c|c|c|c|}
\hline & $\mathrm{n}$ & Mean (sec.) & SD & $F(2,14)$ & $\mathrm{p}$ & \\
\hline CAKM group & 10 & 42.26 & 7.858 & 15.380 & 0.000 & $(1)<(2)^{* *}$ \\
\hline KM group & 10 & 72.14 & 16.719 & & & $(1)<(3)^{* *}$ \\
\hline Keyword group & 10 & 93.24 & 17.280 & & & $(2)<(3)$ \\
\hline
\end{tabular}

$* * p<.01 * p<.05$

A one-way ANOVA was performed on the correct learning rate of the knowledge retrieval aid on each group. The ANOVA results are given in Table 5, and show that the main effect on each group on the correct learning rate had significant differences $(F(2,14)=4.595, p=.033, p<.05)$. The result after multiple analysis show that the correct learning rates of the CAKM group (mean $=0.820, \mathrm{SD}=0.130$ ) were significant higher than those of the Keyword group (mean $=0.340, \mathrm{SD}=0.304$ ) on the correct learning rates. The correct learning rates of the CAKM group (mean $=0.820, \mathrm{SD}=0.130$ ) were higher than those of the KM group (mean $=0.500, \mathrm{SD}=0.291$ ). The KM group (mean $=0.500, \mathrm{SD}=0.291$ ) and Keyword group rates (mean $=0.340, \mathrm{SD}=0.34$ ) show no significant difference with respect to the correct learning rate.

Table 5

ANOVA of the correct learning rate

\begin{tabular}{lllcccc}
\hline & $n$ & Mean & SD & $F(2,14)$ & $p$ & \\
\hline CAKM group & 10 & 0.820 & 0.130 & 4.595 & 0.033 & $(1)>(2)^{*}$ \\
KM group & 10 & 0.500 & 0.291 & & & $(1)>(3)^{*}$ \\
Keyword group & 10 & 0.340 & 0.304 & & $(2)>(3)$ \\
\hline
\end{tabular}

$* * p<.01 * p<.05$

A one-way ANOVA was performed on the evaluation of the total usability of the knowledge retrieval aid on each group. The ANOVA results are given in Table 6. The results show that the main effect on each group on the evaluation of total usability value showed significant differences $(F(2,116)=25.775, p=.000$, $p<.01)$. The results after multiple analysis show that the total usability response value of CAKM group was significantly higher than those of the KM and Keyword groups, and KM group was higher than that of the Keyword group. There exist significant differences in all dimensions of usability (see Table 4), and the three groups also demonstrate significant differences in the response value of the dimension of the system usability. The response value from the CAKM group was higher than that of the KM and the Keyword groups. In this study, we also used the post-hoc analysis, also known as Tukey HSD (honest significant difference) test, to investigate the relationship among these three TAM dimensions with three learning groups. It was found that the response value of the total usability from the CAKM group was higher than that of the KM and the Keyword groups (see Table 7). In addition, the response value of ease of use and intention of use from the KM group was not significant with the Keyword group.

\section{Discussion}

In this study, we designed a context-aware learning system and a CAKM for use in a museum's botanical garden. This learning environment integrated technologies such as wireless networks, handheld devices, and RFID tags. This study further applied the botanical knowledge ontology to develop a semantic and graphical knowledge retrieval aid dubbed CAKM. The purpose was to help learners find learning objects (plants) in the actual environment more efficiently. It also combined a context-aware knowledge map to help learners acquire abundant digital learning resources effectively and to reduce the complexity of information during the search for learning materials.

From a cognitive load perspective, adequate presentation of material can not only lower learners' extraneous cognitive load, but it can also help them to concentrate on learning and building basic models (Sweller \& Chandler, 1994). The intrinsic cognitive load can be lowered through the acquisition and implementation of basic models, while the extraneous cognitive load can be lowered through effective teaching design (Sweller, 1994). When their extraneous cognitive load is lowered, learners are able to increase their germane cognitive loads. When the total of all cognitive loads (intrinsic, extraneous, and germane) is below the load 
limit for working memory (Van Merriënboer \& Sweller, 2005), learning efficiency can be improved. In addition, Firat and Kuzu (2011) proposed that the semantic web could reduce the cognitive loads of learners indexing large amounts of digital resources. The above-mentioned research findings may support the results of this study. Our experimental results indicate that the learning time of the CAKM group was significantly shorter than those of both the KM group and the Keyword group. Also the correct learning rate of the CAKM group was significantly higher than that of the KM group and the Keyword group. The CAKM group was provided with a context-aware knowledge map interface that can lead learners to search learning materials in both digital and actual environments in more efficient ways. This result can be used as reference for museums to build RFID technology and a semantic knowledge map interface into the u-learning environment.

From a system usability perspective, the experimental results show that subjects believed this system allowed them to easily acquire plant knowledge. Subjects also believed that the system's accessibility features and knowledge map enhanced both their motivation to learn and the effectiveness of their learning experience. They also intended to use the system in the future. The results of this study are consistent with those obtained by Peng et al. (2009) and Chen and Huang (2012). The subjects of those studies had a positive attitude towards digital learning via a u-learning system. For example, Peng et al. (2009) showed that experts' and students' perceptions of u-learning systems tend to be positive. They believed that such systems could enhance motivation, interactivity, and learning effectiveness. Chen and Huang (2012) also found that most students believed that the u-learning system was easy to use and effective. Their study also showed that the u-learning system can increase students' motivation to learn, improve learning effectiveness, and enhance students' creativity.

The main subjects of this experiment were non-botany majors, that is, students who were unfamiliar with plant taxonomy. When participants used the keyword approach, they tried to search the digital learning resources using the class, family, genus and species name of the plant on the menu. However, due to their lack of better domain knowledge, they encountered difficulties in searching the digital learning materials, and this hindered their learning. This finding is consisting with the research of Chen and Huang (2013), that prior knowledge is useful for the context of declarative knowledge but not helpful for procedural knowledge. The declarative knowledge represents knowing what a situation is, while the procedural knowledge represents knowing how to carry out a certain task (Zack, 1999). Therefore, the users in the KM and Keyword groups experienced difficulties in learning materials.

\section{Conclusion}

This study used a botany digital resources library to build a teaching resources library, and applied botanical ontology that was developed by expert botanists, to apply RFID-sensing technology in a CAKM with a context-aware function, and also to build a CAKM in a u-learning system. This prototype of a contextaware u-learning system was built in the Botanical Garden of the Museum of Natural Science for experimental purposes. This experimental context was very similar to the actual application context. Therefore, our results can be used as a valuable reference for museums which intend to introduce a ulearning system. This study provided the following research contributions.

First, this study discovered that the learning times of the participants in the CAKM group were considerably lower than those of the KM and Keyword groups. These empirical results show that the knowledge retrieval aid and interface design approach provides a context-aware and ontological knowledge map to improve learning efficiency.

Second, the proposed system provides a CAKM retrieval aid, and the correct learning rate achieved by the participants is substantially higher than that of the KM and Keyword groups, and there is marked difference between the two groups in the correct learning rate. These empirical results show that participants can search related knowledge objects more effectively under the guidance of an ontologically based knowledge map. This also helps participants expand and organise their personal knowledge base more easily, efficiently and meaningfully. For learners who have less domain knowledge, providing context awareness can help them find digital learning materials more efficiently; it is also helpful to offer the taxonomic schematics of the botanical ontology so they can acquire the essential knowledge of botanic categorisation structures. 
Third, with respect to usability analysis and evaluation, the CAKM retrieval aid group showed a high degree of acceptance on the average response values of the usability variables. In Table 7, the average usability reaction values of the CAKM retrieval aid group were all more than 5.5 points. The values of the CAKM group participants for the total usability were substantially higher than those of the KM and traditional Keyword groups.

Finally, this finding confirms those of previous studies, indicating that, without effective tools for helping learners organise their observations in a complex, real-world learning environment, learning performance may be disappointing. A review of publications on the use of computer technology to enhance learning activity revealed that many educational researchers have emphasised the importance of using computer technology to support authentic learning activities (Brown et al., 1989; Donovan et al., 1999; Herrington \& Oliver, 2000; Hwang et al., 2011; Roth, 1992). Kommers, Jonassen, and Mayes (1992) also pointed out that, with proper design, technologies can be applied as knowledge construction tools that students learn with, not from. In addition to its knowledge retrieval function, the CAKM built for this study automatically records learner profiles and marks the pertinent knowledge objects on the knowledge map to help learners systematically build personal knowledge. The results conform with relevant viewpoints of other researchers. This result could imply that with an appropriate user interface design and the use of RFID technology, the system can enhance a museum-like learning experience in context-aware and authentic learning activities.

However, this study still has many limitations, and we have recommendations for further research. Several studies have shown that ontology-based learning tools can effectively promote meaningful learning of abstract knowledge and provide a learning path that can help reduce the learners' cognitive load (Chu et al., 2011; Firat \& Kuzu, 2011; Tsai, Tsai, \& Hwang, 2011). However, this research focuses solely on the effect of CAKM on the learning efficiency of test takers. We have not directly researched cognitive load but have been able to set our findings in context. Future experimental studies can be conducted to test how a ulearning system which employs a CAKM retrieval aid compares with the traditional Keyword retrieval aid in terms of its effect on the user's cognitive load. Furthermore, CAKM, the knowledge retrieval interface developed in this study, used semantic web technology to design the taxonomic schematics of the botanical ontology. Learners can search for content topics through this knowledge retrieval interface, allowing them to find relationships between topics. The traditional keyword retrieval interface provides a keyword menu as the search interface. Learners search for content topics by using the back/forward buttons and an index. Although many cognitive styles have been proposed, Pask's holist-serialist approach was very popular and obviously influenced to students' learning (Mampadi, Chen, Ghinea, \& Chen, 2011; Pask, 1976). Ford and Chen (2001) claimed that if learning environments can be matched with the needs of holists or serialists, then learners can have better learning outcomes. However, this study did not investigate whether individual subjects would prefer a different knowledge retrieval interface based on differences in their cognitive styles. Besides cognitive load, cognitive style should be considered in future research.

In addition, Mampadi et al. (2011) pointed out that learning tools would affect users' achievement and attitudes. The statistical results of our study indicate that subjects' perceptions of the usability of the proposed u-learning system tended to be positive. The responses indicate that the subjects of the CAKM group regarded the u-learning system positively with regard to its usefulness and ease of use. In the future, other factors can be considered and evaluated as to whether they can influence the learning attitudes of users and their intention to use the new technologies in the proposed u-learning system. The other TAMs also could be included in the future to enhance the explanatory capacity and comprehensiveness of this study.

This study was limited by the experimental apparatus, including limitations in the number of handheld devices and RFID readers, making it impossible to conduct experiments with a large sample or to observe how learners were affected by the systematic recording of the learning process over the long term. Therefore, we suggest that, in order to obtain more representative results, experiments with a larger sample should be conducted when introducing the system in the future. In addition, long-term observations should be made in order to increase our understanding of how learners are affected by the recording of the learning process.

For internal consistency and reliability, and to avoid bias and ensure the equivalence of these samples, the subjects of this study were all university students who had no background in botany. However, in the future, botany majors or subjects in other age groups should be recruited in order to determine the effects of different knowledge retrieval aids on the learning performance of experimental subjects from different 
backgrounds.

\section{Acknowledgements}

The authors would like to thank the National Science Council of the Republic of China for financially supporting this research under Contract no. NSC 97-2221-E-025-001, NSC 97-2221-E-025-001, MOST 103-2622-S-005-001-CC3 and MOST 103-2410-H-005-031. We also would like to express our deepest gratitude to the editor and referees in providing us with help and support throughout the study.

\section{References}

Abel, M. H., Benayache, A., Lenne, D., Moulin, C., Barry, C., \& Chaput, B. (2004). Ontology-based organizational memory for e-learning. Educational Technology \& Society, 7(4), 9 8-111. Retrieved from http://www.ifets.info/journals/7_4/11.pdf

Aroyo, L., \& Dicheva, D. (2004). The new challenges for e-learning: the educational semantic web. Educational Technology \& Society, 7(4), 59-69. Retrieved from http://www.ifets.info/journals/7_4/8.pdf

Berners-Lee, T., Hendler, J., \& Lassila, O. (2001). The semantic web. Scientific American, 284(5), 34-43. doi:10.1038/scientificamerican0501-34

Brown, J. S., Collins, A., \& Duguid, P. (1989). Situated cognition and the culture of learning. Educational Research, 18(1), 32-42. doi:10.3102/0013189X018001032

Chandler, P., \& Sweller, J. (1991). Cognitive load theory and the format of instruction. Cognition and Instruction, 8, 293-332. doi:10.1207/s1532690xci0804_2

Chen, C. C., \& Huang, T. C. (2012). Learning in a u-Museum: Developing a context-aware ubiquitous learning environment. Computers \& Education, 59(3), 873-883. doi:10.1016/j.compedu.2012.04.003

Chen, C. C., \& Lin, P. H. (2014). Development and evaluation of a context-aware ubiquitous learning environment for astronomy education. Interactive Learning Environments, doi:10.1080/10494820.2014.915417.

Chen, C. M., \& Li, Y. L. (2010). Personalised context-aware ubiquitous learning system for supporting effective English vocabulary learning. Interactive Learning Environments, 18(4), 341-364. doi:10.1080/10494820802602329

Chen, S. Y., Huang, P. R. (2013). The comparisons of the influences of prior knowledge on two gamebased learning systems. Computers \& Education, 68, 177-186. doi:10.1016/j.compedu.2013.05.005

Chen, Y. S., Kao, T. C., Sheu, J. P., \& Chiang, C. Y. (2008). A mobile scaffolding-aid-based bird-watching learning system. Electronic Edition (IEEE Computer Society DL), 15-22.

Cheng, L., \& Marsic, I. (2002). Piecewise network awareness service for wireless/mobile pervasive computing. Mobile Networks and Applications, 7(4), 269-278. doi:10.1023/A:1015459227426

Chu, H. C., Hwang, G. J., Tsai, C. C., \& Tseng, J. C. R. (2010). A two-tier test approach to developing location-aware mobile learning systems for natural science courses. Computers \& Education, 55, 1618-1627. doi:10.1016/j.compedu.2010.07.004

Chu, K. K., Lee, C. I. , \& Tsai, R. S. (2011). Ontology technology to assist learners' navigation in the concept map learning system. Expert system with applications, 38(9), 11293-11299. doi:10.1016/j.eswa.2011.02.178

Davis, F. D. (1989). Perceived usefulness, perceived ease of use, and user acceptance of information technology. MIS Quarterly, 13(3), 319-339. doi:10.2307/249008

Davis, F. D. (1993). User acceptance of information technology: System characteristics, user perceptions and behavioral impacts. International Journal of Man - Machine Studies, 38, 475-487. doi:10.1006/imms.1993.1022

Dieterle, E. (2004). Wearable computers and evaluation. The Evaluation Exchange, 10(3), 4-5. Retrieved from http://www.hfrp.org/var/hfrp/storage/original/application/8f38769c57fe911b2c356d3b63d7aee5.pdf

Donovan, M. S., Bransford, J. D. \& Pellegrino, J. W. (Eds.). (1999). How people learn: Bridging research and practice. Washington, DC: National Academy Press.

El-Bishouty, M. M., Ogata, H., Rahman, S., \& Yano, Y. (2010). Social knowledge awareness map for computer supported ubiquitous learning environment. Educational Technology \& Society, 13(4), 2737. Retrieved from http://www.ifets.info/journals/13_4/4.pdf

Firat, M., \& Kuzu, A. (2011). Semantic web for e-learning bottlenecks: disorientation and cognitive overload. International Journal of Web \& Semantic Technology, 2(4), 55-65. 
doi:10.5121/ijwest.2011.2404

Ford, N., \& Chen, S. Y. (2001). Matching/mismatching revisited: An empirical study of learning and teaching styles. British Journal of Educational Technology, 32(1), 5-22. doi:10.1111/14678535.00173

Gašević, D., Jovanović, J., \& Devedžić, V. (2007). Ontology-based annotation of learning object content. Interactive Learning Environments, 15(1), 1-26. doi:10.1080/10494820600968203

Gascueña, J. M., Fernández-Caballero, A., \& González, P. (2006). Domain ontology for personalized elearning in educational systems.In Kinskuk, R. Koper, P. Kommers, P. Kirscner, D. G. Sampson, \& W. Didderen (Eds.), Proceedings of the Sixth IEEE International Conference on Advanced Learning Technologies (pp. 456-458). Piscataway, NJ: IEEE. doi:10.1109/ICALT.2006.1652470

Gruber, T. R. (1993). A translation approach to portable ontology specifications. Knowledge Acquisition, 5, 199-220. doi:10.1006/knac.1993.1008

Henze, N., Dolog, P., \& Nejdl, W. (2004). Reasoning and ontologies for personalized e-Learning in the semantic web. Educational Technology \& Society, 7(4), 82-97. Retrieved from http://www.ifets.info/journals/7_4/10.pdf

Herrington, J., \& Oliver, R. (2000). An instructional design framework for authentic learning environments. Educational Technology Research and Development, 48(3), 23-48. doi:10.1007/BF02319856

Hwang, G. J., Shi, Y. R., \& Chu, H. C. (2011). A concept map approach to developing collaborative Mindtools, for context-aware ubiquitous learning. British Journal of Educational Technology, 42(5), 778-789. doi:10.1111/j.1467-8535.2010.01102.x

Kalyuga, S., Ayres, P., Chandler, P., \& Sweller, J. (2003). The expertise reversal effect. Educational Psychologist, 38(1), 23-31. doi:10.1207/S15326985EP3801_4

Kommers, P., Jonassen, D. H., \& Mayes, T. (Eds.) (1992). Cognitive tools for learning. Heidelberg: Springer. doi:10.1007/978-3-642-77222-1

Kwon, O., Choi, K., \& Kim, M. (2007). User acceptance of context-aware services: Self-efficacy, user innovativeness and perceived sensitivity on contextual pressure. Behaviour \& Information Technology, 26(6), 483-498. doi:10.1080/01449290600709111

Lanir, J., Kuflik, T., Wecker, A. J., Stock, O., \& Zancanaro, M. (2011). Examining proactiveness and choice in a location-aware mobile museum guide. Interacting with Computers, 23, 513-524. doi:10.1016/j.intcom.2011.05.007

Looi, C. K., Seow, P., Zhang, B. H., So, H. J., Chen W., \& Wong, L. H. (2010). Leveraging mobile technology for sustainable seamless learning: A research agenda. British Journal of Educational Technology, 41(2), 154-169. doi:10.1016/j.intcom.2011.05.007

Mampadi, F., Chen, S. Y., Ghinea, G., \& Chen, M. P. (2011). Design of adaptive hypermedia learning systems: A cognitive style approach. Computers \& Education, 56, 1003-1011. doi:10.1016/j.compedu.2010.11.018

Mandato, D., Kovacs, E., Hohl, F., \& Amir-Alikhani, H. (2002). CAMP: a context-aware mobile portal. Communications Magazine. IEEE, 40(1), 90-97. doi:10.1109/35.978054

Mehrens, W. A., \& Lehmann, I. J. (1987). Using standardized tests in education. New York, NY: Longman.

Nunnally, J. C. (1978). Psychometric theory (2nd ed.). New York, NY: McGraw-Hill.

Paas, F., Renkl, A., \& Sweller, J. (2003). Cognitive load theory and instructional design: Recent developments. Educational Psychologist, 38, 1-4. doi:10.1207/S15326985EP3801_1

Pachler, N., Cook, J., \& Bachmair, B. (2010). Appropriation of mobile cultural resources for learning. International Journal of Mobile and Blended Learning, 2(1), 1-21. doi:10.4018/jmbl.2010010101

Pask, G. (1976). Styles and strategies of learning. British Journal of Educational Psychology, 46, 128148. doi:10.1111/j.2044-8279.1976.tb02305.x

Pegrum, M., Oakley, G., \& Faulkner, R. (2013). Schools going mobile: A study of the adoption of mobile handheld technologies in Western Australian independent schools. Australasian Journal of Educational Technology, 29(1), 66-81. Retrieved from http://ascilite.org.au/ajet/submission/index.php/AJET/index

Peng, H., Chuang, P. Y., Hwang, G. J., Chu, H. C., Wu, T. T., \& Huang, S. X. (2009). Ubiquitous performance-support system as mindtool: A case study of instructional decision making and learning assistant. Educational Technology \& Society, 12 (1), 107-120. Retrieved from http://www.ifets.info/journals/12_1/9.pdf

Roth, W. M. (1992). Bridging the gap between school and real life. Social Science and Mathematics, 92(6), 307-317. doi:10.1111/j.1949-8594.1992.tb15596.x 
Sowa, J. F. (2000). Knowledge representation: Logical, philosophical, and computational foundations. Pacific Grove, CA: Brooks/Cole.

Sun, J. N., \& Hsu, Y. C. (2012). An experimental study of learner perceptions of the interactivity of webbased instruction. Interacting with Computers, 24(1), 35-48. doi:10.1016/j.intcom.2011.11.001

Sweller, J. (1994). Cognitive load theory, learning difficulty and instructional design. Learning and Instruction, 4, 295-312. doi:10.1016/0959-4752(94)90003-5

Sweller, J., \& Chandler, P. (1994). Why some material is difficult to learn. Cognitive and Instruction, 12(3), 185-233. doi:10.1207/s1532690xci1203_1

Tergan, S. O., Gräber, W., \& Neumann, A. (2006). Mapping and managing knowledge and information in resource-based learning. Innovation in Education and Teaching International (IETI), 43(4), 327-336. doi:10.1080/14703290600973737

Tsai, P. S., Tsai, C. C., \& Hwang, G. H. (2011). College students' conceptions of context-aware ubiquitous learning: A phenomenographic analysis. The Internet and Higher Education, 14(3), 137-141. doi:10.1016/j.iheduc.2011.01.004

Uschold, M., \& Gruninger, M. (1996). Ontologies: Principles, methods and applications. The Knowledge Engineering Review, 11(2), 93-136. doi:10.1017/S0269888900007797

Van Merriënboer, J. J. G., \& Sweller, J. (2005). Cognitive load theory and complex learning: Recent developments and future directions. Educational Psychology Review, 17, 147-177. doi:10.1007/s10648-005-3951-0

Wang, S. L., \& Wu, C. Y. (2011). Application of context-aware and personalized recommendation to implement an adaptive ubiquitous learning system, Expert Systems with Applications, 38, 1083110838. doi:10.1016/j.eswa.2011.02.083

Weiser, M. (1993). Some computer science Issues in ubiquitous computing, Communications of the ACM, 137-143. doi:10.1145/159544.159617

Yalcinalp, S., \& Gulbahar, Y. (2010). Ontology and taxonomy design and development for personalized web-based learning systems. British Journal of Educational Technology, 41(6), 883-896. doi:10.1111/j.1467-8535.2009.01049.x

Yang, S. J. H., Okamoto, T., \& Tseng, S. S. (2008). Context-aware ubiquitous learning. Journal of Educational Technology and Society, 11(2), 1-128. Retrieved from http://www.ifets.info/journals/11_2/1.pdf

Zack, M. H. (1999). Managing codified knowledge. Sloan Management Review, 40(4), 45-58. Retrieved from http://sloanreview.mit.edu/article/managing-codified-knowledge/

Corresponding author: Chia-Chen Chen, emily@nchu.edu.tw

Australasian Journal of Educational Technology (c) 2015.

Please cite as: Wang, S-L., Chen, C-C. \& Zhang, Z. (2015). A context-aware knowledge map to support ubiquitous learning activities for a u-Botanical museum. Australasian Journal of Educational Technology, 31(4), 470-485. 